\title{
Jorge Teillier: La inscripción de una historia familiar
}

\author{
Jorge Teillier: The inscription of a family history ${ }^{*}$
}

\begin{abstract}
Alida MaYne-Nicholls Verdi
Pontificia Universidad Católica de Chile. Santiago, Chile

amayne@uc.cl.

\section{RESUMEN}

El presente artículo propone una lectura de cinco poemas de Jorge Teillier, en los que se utilizan las comidas y bebidas como metáforas del sujeto poético. Este sujeto se encuentra en una posición de desarraigo e inicia un viaje a través de la memoria hacia la infancia, con el fin de realizar una reconstrucción de ésta, al punto de crear una inscripción de su historia familiar.
\end{abstract}

Palabras clave: Teillier, poesía chilena, comidas y bebidas, infancia, viaje por la memoria.

\section{ABSTRACT}

This paper proposes a reading of five poems from Jorge Teillier, in which food and beverage become metaphors for the poetic subject. This subject is in an uprooting position, so he begins a journey through memory towards childhood, with the purpose to perform a reconstruction of it, creating, at the same time, an inscription of his family history.

Keywords: Teillier, Chilean poetry, food and beverage, childhood, journey through memory.

Recibido: 09.04.2012. Aceptado: 26.08.2012.

* Este artículo se inscribe dentro del proyecto Fondecyt No 11.20.264, "Comidas y bebidas en la poesía chilena”. 
ada semana lavo, pelo y corto en trozos diversos vegetales: zapallo ca-
mote, zapallo italiano, repollo morado, zanahorias, tomate, papas. A veces les agrego carne de vacuno, otras pollo. Lo pongo todo en una olla con un poco de agua y agrego orégano, lo tapo y a cocer. Es el ritual de preparación de la comida de mi hijo, que se prolonga cada día cuando al almuerzo abre la boca y come hasta la última cucharada. Y cada tarde cuando comienza a exigir la cena para poder ponerse pijama e irse a dormir. No me cabe duda que en esos momentos seguimos construyendo un vínculo y también una historia en común. Lo que me lleva a pensar que la historia propia se hace en la vida cotidiana, mediante pequeñas pero significativas acciones.

Son aquellas tareas diarias las que trata de rescatar Jorge Teillier (19351996) en su poética. Pienso, por ejemplo, en "el licor de guindas que preparó la abuela y las manzanas puestas a guardar" (1995: 17) que menciona en el poema "Otoño secreto". El esfuerzo de hacer la comida con mis propias manos tiene un sentido de generar memoria, porque cuando me enfrento a la sociedad actual me pregunto cuáles serán los eventos cotidianos a que nos aferraremos cinco, diez o veinte años más tarde, porque una sociedad basada en la productividad y la permanencia cada vez más prolongada en el lugar de trabajo, atenta contra todo aquello cotidiano, convirtiendo la existencia diaria desde el comienzo en un ser en el desarraigo; de tal manera que la factura diaria de la papilla del bebé se convierte en la compra diaria del colado preparado que espera en un estante del supermercado.

Pensemos en lo que nos dice Michel de Certeau: si el sostén de la novela familiar es el "hacer-la-comida” (Certeau, Giard y Mayol, 1999: 159), ¿cuál es la novela que terminaremos escribiendo? Siempre de acuerdo a Certeau, "cada hábito alimentario compone una minúscula encrucijada de historias" (1999: 175), pero se trata de historias personales, íntimas. Es esto lo que encontramos en los poemas de Teillier: "Otoño secreto", "Huerto", "Día de feria", "Sentados frente al fuego" y "La fiesta" ${ }^{1}$, un deseo de recuperación de la cotidianidad de la infancia y adolescencia, que están teñidas de sabores y olores por las comidas.

Podríamos decir que en un primer nivel de lectura ${ }^{2}$, las comidas en Teillier se convierten en elementos que desencadenan, tanto sensaciones como memorias, puesto que el recuerdo es guiado y animado por esas manzanas,

${ }^{1}$ Teillier, 1995: 17-18, 25-27, 31-33, 36-37.

${ }^{2}$ Riffaterre sostiene que una primera interpretación o lectura llamada heurística, permite aprehender el significado del poema, pero buscando el sentido referencial de las palabras. Por tanto, es en esta lectura que podemos notar los quiebres en el lenguaje que llevarán a la segunda lectura, que es la retroactiva y de carácter hermenéutico (1984: 5). 
el pan horneado, la harina tostada, la sopa caliente, las cerezas sacadas de los árboles. Los alimentos nos muestran un camino orgánico: o bien de preparaciones caseras, o bien de tomar aquello que nos da la naturaleza, y en ese sentido nos conecta con la vida familiar o privada, más que con el ambiente público y masivo, que podría referirnos por ejemplo al supermercado, o artificial si nos remitiera a comidas congeladas, enlatadas, precocidas, entre otras.

Cuando pensamos en Teillier, nos encontramos con un poeta que pertenece al canon, de hecho es un autor que ha sido antologado en variadas ocasiones y a quien se lo considera uno de los representantes más destacados de nuestra literatura. Su presencia en antologías es temprana, y así apareció en Poetas universitarios, edición de 1956, mismo año en que él estaba publicando su primer poemario Para ángeles y gorriones. Naín Nómez lo incluye en su libro Poesía chilena contemporánea: breve antología crítica, en la cual la intención era-como él mismo lo explicita en la introducción-, presentar una "selección de textos de los principales poetas chilenos contemporáneos, aquellos que constituyen un aporte relevante a la literatura hispanoamericana y universal" (9). Así Teillier aparecerá junto a Gabriela Mistral, Vicente Huidobro, Pablo de Rokha, Pablo Neruda, Humberto Díaz Casanueva, Nicanor Parra, Gonzalo Rojas y Enrique Lihn. Específicamente sobre Teillier, Nómez escribirá que "dialoga con poetas de Europa (Paul Verlaine, Rainer María Rilke, François Villon, René Guy Cadou), Hispanoamérica (Rubén Darío, López Velarde, Luis Carlos López) y Chile (Huidobro, Omar Cáceres, Pezoa Véliz, Romeo Murga), pero sobre todo con sus lecturas de infancia" (1992: 13-14), es decir, lo ubica en el campo literario a la par de nombres destacados del panorama mundial ${ }^{3}$.

De la misma manera, Alfonso Calderón ${ }^{4}$ destacará a Teillier por haber realizado "aportes fundamentales (...) a la lírica nacional", entre ellos: la creación de una mítica poética, búsqueda de un lenguaje de núcleo emotivo, establecimiento de una temporalidad subjetiva y recuperación de una tradición literaria dispersa (1971: 152). Es decir, el poeta no sólo escribió, sino que dejó una marca en la tradición poética nacional. Cuando se realizan aproximaciones críticas a la poesía de Teillier, nos encontramos con lecturas como la del paraíso perdido, la presencia de la memoria, la recuperación de la relación entre el hombre y el mundo. Así, por ejemplo, Jaime Valdivieso

\footnotetext{
${ }^{3}$ Nómez también sitúa la propuesta poética de Teillier frente a otras corrientes chilenas, tales como las vanguardias y la antipoesía, al lado de las cuales la escritura del poeta establecería su propio y distintivo lugar (1992: 328).

${ }^{4}$ Calderón (2005) también incluye a Teillier en su propia selección.
} 
(1997), postula que en sus poemas hay una "realidad que se sustituye por la memoria y la fantasía para hacerla más respirable" y Naín Nómez propondrá que en su obra muestra "una aldea que es la imagen del universo y en cuyo reflejo se superpone al paisaje visible un paisaje de ensueño y a la infancia real aquélla de la maravilla original y mítica" (1992: 325).

Teniendo en cuenta esas visiones, propongo acercarme a Teillier desde la autobiografía, considerando a sus poemas no sólo como creaciones totalmente ficcionales, sino como provenientes de una experiencia particular que busca plasmarla en un texto -dar testimonio- y que como tal permite buscar el referente extratextual de la narración ${ }^{5}$. Para esto me apoyo en Leonor Arfuch y en su planteamiento de que es posible encontrar voces autobiográficas que "pueda[n] dar razón de un mito de origen, una genealogía, un devenir, y defender por lo tanto unas condiciones de existencia" (2002: 80), lo cual-como veremos luego- es posible de observar en los poemas de Teillier.

Como planteaba anteriormente, me centraré en cinco poemas de Jorge Teillier. Aunque cada uno tiene sus particularidades, es posible leerlos como un todo, como un poema único, por cuanto la posición de enunciación que encontramos es la misma. Por lo tanto, es posible proponer una hipótesis ${ }^{6}$ común para estos poemas: el sujeto lírico se encuentra en una posición de desarraigo y extrañamiento: no es capaz de encontrar su lugar en el mundo presente, puesto que en éste se hace patente la pérdida. Por tal motivo, el sujeto inicia un viaje a través de la memoria hacia la infancia, la casa familiar, la tierra natal-que es provinciana y ligada al trabajo de la tierra-, con el fin de contrarrestar la pérdida. Sin embargo, como estoy poniendo el acento en el enfoque autobiográfico de los poemas, dicha travesía consiste no en realizar una construcción de la infancia desde la nada, sino en hacer una reconstrucción del pasado vivido.

En esa actualización del pasado la inclusión de comidas y bebidas tiene una orientación metafórica, de tal modo que los alimentos son metáforas del sujeto mismo -en distintos niveles y con algunas diferencias entre los textos-, lo que cobra sentido en las imágenes de la comida en los poemas, en particular la sensación de que están más vivas que los cuerpos del presente de la enunciación. Retomo entonces el problema cultural: la sociedad actual

${ }^{5}$ La teoría acerca de la autobiografía muestra el campo ambiguo que ésta representa, por lo cual iremos precisando qué entendemos por autobiografía a medida que profundicemos en su conexión con los textos de Teillier.

${ }^{6}$ Me baso en la noción de "hipótesis poética" de Ricoeur, según la cual en la lectura se realiza "una proposición de un mundo en el modo imaginativo, ficticio" (2001: 342). Es decir, a partir de la referencia literal que entregan los poemas de Teillier, estoy postulando la propuesta de lectura que guiará la presentación de los poemas. 
está olvidando la importancia de hacer-la-comida como constructora de la novela familiar. En vez de eso, nos encontramos frente a un consumo que se hace fuera del ámbito privado, de tal manera que reemplazamos la novela familiar por estadísticas y resultados comerciales: índices de consumo, proliferación del delivery y la comida rápida, índices de obesidad y diabetes. En los poemas de Teillier, sin embargo, aquello artesanal o ligado al trabajo manual que implica el cocinar todavía está presente. Pensemos entonces en el modelo de los poemas ${ }^{7}$. En primer lugar nos encontramos con que están escritos en verso libre, es decir, los versos tienen distintos números de sílabas y no hay rima regular. Según Forradellas y Marchese, esto significa un alejamiento con respecto a "cualquier constricción externa", lo que reproduciría un ritmo del pensamiento más que de la escritura (1986: 417). Efectivamente, en los poemas seleccionados no hay rima presente, lo que le da una naturalidad a los textos que es concordante con el lenguaje cotidiano con el cual el sujeto se expresa; lo mismo sucede con el número de sílabas.

Acerca del modelo, llama también la atención el uso de una figura como la personificación en algunos de ellos. Por ejemplo, en "Otoño secreto" tanto el licor de guindas como las manzanas "conservan su alegría" (1995: 17) y en "Huerto" son "[l]as manos del viento [las que] remecen los árboles de la huerta" (26). La utilización de esta figura no es gratuita, sino que muestra que los objetos, las cosas, incluso los fenómenos naturales, tienen una conexión con la gente, y que están llenos de vida y cargados de emotividad, como las personas del ambiente familiar y provinciano desde el que sujeto se posiciona.

En cada uno de los poemas podemos identificar matrices específicas, sin embargo también hay una sola gran matriz ${ }^{8}$ que cruza todos los textos: el ansia de recuperar la vida de la infancia. Entenderé infancia como la vida relacionada con el hogar, pero también con las primeras experiencias. Es decir, es la primera etapa de la vida, la ligada a la familia, pero también involucra el primer amor ("Sentados frente al fuego") o el primer reconocimiento del otro indígena y campesino ("Figuras de greda"). Lo interesante es que se trata de experiencias que son captadas desde la inocencia de unos ojos que ven las cosas por primera vez, pero pasando por el cedazo de la desilusión que provoca la pérdida de esa inocencia. Así tenemos que en "Otoño secreto", la infancia es la primavera en que se lo educaba y cuidaba con amor, como se prepara el licor de guindas y se guardan las manzanas en el seno familiar.

\footnotetext{
${ }^{7}$ Para Riffaterre, el modelo es la forma en que se manifiesta la estructura del poema (1984: 19).

${ }^{8}$ Utilizo el concepto de matriz de Riffaterre: una oración mínima, literal e hipotética a partir de la cual se puede realizar una lectura compleja y no literal del poema (Ibíd).
} 
Esa es la verdad que él amaba. Por el contrario, el crecer, el independizarse pudo haberle dado conocimiento, pero al mismo tiempo el espíritu se vuelve solitario, perdido, quebrado como las ramas. Lo relaciono con el poema de Gabriela Mistral, "Pan":

En mis infancias yo le sabía

forma de sol, de pez o de halo,

y sabía mi mano su miga

y el calor de pichón emplumado...

Después le olvidé, hasta este día [...] (2010: 256).

En los versos anteriores podemos ver que el sujeto sabía cuál era su identidad durante la infancia, el olvido llegó después, con la educación formal. De la misma manera, el conocimiento y el alejamiento del hogar han hecho que el sujeto de "Otoño secreto" olvidara quién era. Es interesante que así como Mistral titula "Pan" a su poema, el mismo alimento aparece al comienzo del texto de Teillier: "no se puede nombrar ni el pan". Así conectamos con la isotopía del lenguaje y la idea de pan en Teillier: el pan es el sujeto; es el sujeto el que no se puede nombrar, de tal manera que hay una crisis del lenguaje ${ }^{10}$ que es la crisis del sujeto. Siguiendo a Kristeva ${ }^{11}$, es el lenguaje el que permite que el hombre se constituya a sí mismo, pero en el poema tanto lenguaje como sujeto se encuentran en un estado de inadecuación. Para hacer frente a esa condición, es necesario regresar y esa vuelta se hace a través de la conformación de la novela familiar.

Frente a ese panorama, el sujeto sólo puede soñar con el sol-el cuerpo es el granero-, pero siempre teniendo conciencia de ese secreto terrible, que no

9 "Pan" pertenece al poemario Tala, originalmente publicado en 1938, y aparece bajo el subtítulo de "Materias". He trabajado con la antología de Gabriela Mistral editada en 2010 por la Real Academia Española y la Asociación de Academias de la Lengua Española.

${ }^{10}$ La crisis del lenguaje ha sido una problemática desde comienzos del siglo XX. En palabras de Theodor W. Adorno dicha crisis se leía "en términos de una necesidad específica de expresión que en sí el lenguaje ya no satisface" (2003: 519). Adorno está haciendo referencia a los poetas alemanes Rudolf Borchardt y Hugo von Hofmannsthal. En esos tiempos, la crisis del lenguaje tenía que ver con el quiebre general de las humanidades con la forma de ver el mundo heredada desde el saber clásico (Rubio Tovar, 2005: 121). Sin embargo, la crisis del lenguaje seguirá manifestándose y con posterioridad a la Segunda Guerra Mundial estará unida a la crisis de la representación, que se vincula a la idea de cómo es posible narrar el mundo -con qué imágenes, con qué palabras- después de los horrores y la destrucción del conflicto.

${ }^{11}$ Kristeva hablará de hecho de "inmersión nominal" en relación con la idea de la adhesión del hombre al Padre, es decir, está fundamentada no en que Dios es ley, sino en que el amor es el verbo (2000: 122). 
quiere admitir: que no es posible regresar al pasado de completitud más que a través de una "mentira inventada" (Teillier, 1995: 17), es decir, una ficción que produce un recuerdo perfecto, pero efímero.

Como hipograma ${ }^{12}$, me centré en un pasaje de la novela Heidi. Antes de comentar este extracto, primero lo pongo en contexto. Heidi, una niña huérfana, es llevada por su tía a vivir en los Alpes con su abuelo. Heidi no conoce al anciano que vive bastante recluido en una casa en las montañas y sin mayor contacto con el pueblo más cercano. El episodio narrado ocurre el día de la llegada de Heidi, que es sin previo aviso y que, por lo tanto, sorprende a un anciano que pareciera reacio a cuidar a una niña. Aunque son familia por consanguinidad, no han establecido lazos afectivos, ni siquiera se conocen:

Creo que será mejor que vayamos a comer algo- respondió el abuelo. ¿Qué te parece a ti?

En su afán de prepararse la cama, Heidi había olvidado todo lo demás. Pero al oír hablar de comida, advirtió súbitamente que, en efecto, sentía hambre, porque aparte del trozo de pan y la taza de café muy diluido que había tomado antes de salir del pueblo, no había comido nada más aquel día. De aquí que respondiera muy animada:

-Sí, sí, vámonos a comer algo.

-Pues bien, bajemos, ya que estamos de acuerdo.

Y seguido de la niña, volvió a la única habitación de la casita.

El Viejo se dirigió al hogar, descolgó un caldero grande que colgaba de la cadena sobre los rescoldos del hogar, lo reemplazó por uno más pequeño y se sentó sobre un taburetito para avivar el fuego; al poco tiempo las llamas brillaban con alegre fuego. Pronto empezó a hervir el contenido del pequeño caldero; mientras tanto, el abuelo había cogido unas tenazas de hierro y sostenía sobre el fuego un gran trozo de queso, dándole vueltas con lentitud hasta que estuvo dorado. Heidi había seguido aquellos preparativos con mucha atención; de pronto, tuvo una idea y se alejó del hogar y empezó a ir y venir del armario a la mesa. El abuelo concluyó por fin junto al hogar y se acercó a la mesa con un cazo en la mano y el queso asado en la otra sujeto al extremo de las tenazas. Cuando se aproximó a la mesa, la halló ya puesta; sobre ella reposaba un pan, dos platos hondos y dos cuchi-

${ }^{12}$ Entiendo por hipograma lo planteado por Riffaterre: un texto desde el cual el lector analiza el poema y le da sentido. Dicho texto puede ser tanto literario como de carácter cultural y es parte de los conocimientos que el lector posee con anterioridad a la lectura del poema que está analizando (1984: 23). 
llos. Heidi era una niña muy observadora, había comprendido que todo aquello que antes viera en el armario, haría falta para comer.

-Muy bien, pequeña: me gusta que sepas pensar un poco- dijo el anciano en tono de alabanza-, pero aún falta algo en la mesa (2000: 20).

El relato de la primera comida juntos de Heidi y su abuelo, se convierte en un punto de apertura, en el que no sólo es posible vislumbrar que podrán convivir, sino que podrán llegar a convertirse en abuelo y nieta. Es interesante que la autora Juana Spyri (2000) involucra a ambos personajes en el episodio: mientras el abuelo prepara la comida, Heidi pone la mesa para los dos. Lo que tiene lugar es mucho más que una práctica destinada a saciar el hambre. Juntos están escribiendo su novela familiar, es decir, están creando vínculos, están escribiendo una historia en común.

Asimismo, el pasaje nos está diciendo cómo es la vida del abuelo, sencilla, austera, campesina, laboriosa, por cuanto producen su propio alimento y autosustentable en el sentido de que comen aquello que pueden producir. En los poemas de Teillier también encontramos la inscripción de un vínculo, por cuanto la infancia añorada no es en soledad, sino en el contexto familiar y local. Así tenemos que en "Huerto" el sujeto lírico recuerda "la harina tostada en las mañanas" (1995: 26), que no es simplemente la expresión melancólica de un hábito del pasado, sino que ese verso implica un alguien que preparaba el desayuno y otros con quienes se compartía, habla de los vínculos y las relaciones del diario vivir que quedaron en el pasado.

En este poema el sentimiento de pérdida es claramente un estado de áni$\mathrm{mo}^{13}$. Ese estado atraviesa todos los textos, pero en "Huerto" se manifiesta ya en el modelo, por cuanto podemos identificar el tópico ubi sunt (“¿dónde están?”):

"Dónde están, dónde van a parar, caídos de árboles de otra época, remecidos por el viento extranjero, la harina tostada en las mañanas, el pozo que no le contaba a nadie la historia de los primeros besos, el croar campesino de ranas a medianoche" (1995: 26).

${ }^{13}$ Estado de ánimo o mood según la concepción de Ricoeur en Metáfora viva, según la cual no estamos hablando del sentimiento que el sujeto lírico tiene en determinado momento, sino de la concepción del mundo que tiene y que se plasma en los versos (2001: 342). 
Este tópico no trata sólo de una enumeración de cosas, personas, momentos, que se fueron, sino que nos ubica frente a un lamento: en el presente quedan tan solo ruinas y se gime ante la desaparición de aquello glorioso y valorado en el pasado. Cedomil Goic añade a esto que el tópico incluye un cuestionamiento acerca de la condición humana:

La pregunta no se dirige, sin más, a averiguar la fugacidad del tiempo o la acción del olvido, sino a inquirir por la condición del hombre, por saber si, entonces como ahora, el hombre sobrellevó una degradada existencia, si vivió sujeto a la deformación que hace hoy en día al hombre menos humano: si hambre, miseria, dolor, expolio, se hallaron unidos a la obra portentosa (1992: 85).

Para Goic el ubi sunt es el tópico por excelencia de la elegía. Si buscamos en un diccionario literario encontraremos como definición de elegía: "Poema lírico extenso que expresa sentimientos de dolor por la desgracia de uno o varios seres estimados" (Ayuso de Vicente, García Gallarín y Solano Santos, 1997: 116). Por su parte, Goic mencionará que tiene partes bien definidas: "consideraciones sobre la muerte, lamentación, panegírico y consolación" (1992: 71). ¿Es posible que la elegía sea el modelo de "Huerto"? Ciertamente no se trata de un poema extenso: está compuesto por tres estrofas, cada una de un número diferente de versos que en total suman veinte. Luego, observemos si se pueden identificar todas o algunas de las partes de una elegía: muerte, lamentación, panegírico y consolación. En el caso de la muerte, pienso en los siguientes versos "(...) y caen sobre el pasto / pequeñas frutas descarnadas, / picoteadas por los pájaros” (1995: 26). En lamentación está el verso: "Dónde están, dónde van a parar" (26). En la parte del panegírico ${ }^{14}$ pienso en: "(...) el pozo que no le contaba a nadie / la historia de los primeros besos" (26). Y finalmente no encuentro versos que den cuenta de una consolación.

Lo que busco mostrar es que "Huerto" sí utiliza la elegía como modelo, pero a través de modificaciones estilísticas, puesto que el poema debe ser coherente con la poética de Teillier, en relación con la simpleza del lenguaje. Asimismo, los poemas son de una extensión reducida, por lo cual la elegía ajusta su forma, el modelo no es exacto, pero sí reconocible. La muerte en el caso de este poema es la de las frutas, que caen descarnadas. La imagen es

\footnotetext{
${ }^{14}$ Entendiendo panegírico como: "Encomio o discurso en el que se alaba a una persona ilustre" (Ayuso de Vicente, García Gallarín y Solano Santos, 1997: 279). En este caso, el encomiado es el pozo, que toma rasgos humanos a través de la personificación. Se valora su discreción y lealtad.
} 
literal: frutas descarnadas corresponde a frutas muertas ${ }^{15}$, que no solo caen, sino que en el pasto son picoteadas por los pájaros, como gusanos que consumen el cuerpo de una persona enterrada.

Luego comienza la lamentación, que aparece tanto en la segunda como en la tercera estrofa. La segunda comienza con el verso "Dónde están, dónde van a parar" y la tercera con el verso "Dónde han caído". El panegírico es breve: primero habla de los árboles de otras épocas, luego de la harina tostada que se consumía en las mañanas, luego del pozo leal, capaz de guardar secretos -es al pozo al que se alaba de manera más literal-y por último menciona el croar campesino de las ranas. Pareciera que no se trata sólo de alabar a alguien, sino un lugar, un tiempo, un espacio preciso que se encuentra en el pasado, que tiene que ver con la existencia cotidiana, en que se tomaba el harina tostada al desayunar, y donde por la noche se escuchaba el canto de las ranas. Se trata de un ambiente rural, campesino y pobre.

Por último deberíamos encontrar la consolación, pero en vez de eso prosigue el lamento: nuevamente las frutas muertas, olvidadas, picoteadas, y también la charla de la niña, que ha desaparecido, llevada a una aldea muerta a la que compara con el "reflejo de la luna en el vidrio roto del granero" (1995: 27). Lo que sucede es que no hay consuelo posible, porque el pasado es irrecuperable. Podemos rememorar los árboles, la comida, el pozo, el primer amor juvenil, el ambiente campesino, pero eso no lo traerá de vuelta.

Sin embargo, aunque no es posible volver a vivir el pasado, sí es posible narrarlo y actualizarlo en la narración, lo que me posiciona nuevamente en la hipótesis y en su conexión con la lectura de los poemas desde una perspectiva autobiográfica. Cuando propongo esta mirada, no lo hago desde la rigidez que podríamos encontrar en algunos teóricos como Philippe Lejeune, que llegó a definir la autobiografía como un "relato retrospectivo en prosa que una persona real hace de su propia existencia, poniendo énfasis en su vida individual y, en particular, en la historia de su personalidad" (1991: 48). Según esa descripción, los poemas de Teillier no serían autobiográficos, pero sí podemos encontrar que hay un relato retrospectivo en esos versos: como el recuerdo de las figuras de greda que vendían su mano de obra campesina en "Día de feria" y también en el encuentro de los enamorados en "Sentados frente al fuego". Sí estoy pensando en el concepto de espacio biográfico, que -como postula Arfuch- permite ver más allá de las limita-

\footnotetext{
${ }^{15}$ A partir del diccionario de la RAE, la definición de descarnado puede ser la de algo "crudo o desagradable, expuesto sin paliativos" y la de descarnada (en femenino), es muerte, que tendría como símbolo la figura del esqueleto (768).
} 
ciones que implica el género y centrarnos en cambio en el hecho de que hay un sujeto que ha tomado una posición desde la cual habla y que podemos encontrar la referencia de ese sujeto en el ámbito real (2002: 101). Al hablar de referencia no estamos hablando de equivalencia, es decir, no estoy estableciendo que el sujeto de los poemas es Jorge Teillier, sino que podemos encontrar una relación entre ambos. Tenemos conciencia de que el ambiente rural de los poemas es el ambiente en que Teillier creció. ¿Quiere decir esto que encontramos un relato mimético, fiel de lo que aconteció cuando Teillier era niño y adolescente? No es eso lo que buscamos, después de todo "toda narración de un yo es una forma de ficcionalidad" (Pozuelo Yvancos, 2006: 24), es decir, que los recuerdos y la experiencia real de Teillier fueran material para la conformación de sus versos, no implica que haya un esfuerzo por tratar de escribir un texto informativo. Existe sí un esfuerzo por captar "el tiempo cotidiano, las costumbres, el trazado de historias singulares, grupales, generacionales, la afirmación de nuevos mitos fundacionales y políticas de identidad" (Arfuch, 2002: 84).

Teillier estaba recuperando esa historia familiar, pero cómo la plasmara dependía, por supuesto, de él. En este sentido tal vez nos podamos remitir al concepto de autoficción que Arfuch también presenta, según lo cual el relato es conscientemente ficcionalizado y liberado de la pretensión de ser fiel al referente extratextual ${ }^{16}$ (2002: 98). De la misma manera, podemos ver desde esa perspectiva textos como Décimas de Violeta Parra o Veneno de escorpión azul de Gonzalo Millán, en que lo autobiográfico es elaborado, ficcionalizado, poetizado, desde sus subjetividades ${ }^{17}$.

En la ficcionalización que realiza Teillier encontramos una clara metáfora cognitiva, según la cual los alimentos corresponden a la identidad del sujeto, de tal manera que en "Huerto" "las pequeñas frutas descarnadas" (1995: 26) corresponden a la identidad devorada por el paso del tiempo, es decir, la inadecuación del sujeto es tal que su metáfora es la de una fruta podrida y picoteada. De una manera semejante en "La fiesta" la metáfora también tiene que ver con el alimento y el sujeto: el pan es el hombre, que vuelve a ser niño (trigo). En los últimos versos se menciona tanto al pan como al vino, y sobre este último se sostiene que es "el mensaje que nos envía el cielo liberado" (37). El vino no parece estar al mismo nivel que el pan, es decir,

${ }^{16}$ Arfuch se apoya en el concepto de autoficción de Régine Robin.

${ }^{17}$ Ambos autores hablan desde el yo. Mientras Parra realiza en relato de ciertos episodios de su vida, da cuenta también de una historia de las clases populares. En tanto, Millán escribe un diario que registra - de diversas maneras, incluyendo, por supuesto, el verso-, la enfermedad que terminaría con su vida. 
si el pan es el cuerpo adulto que regresa a la infancia, el vino podría ser la vida. Hago esta relación teniendo en cuenta la presencia del vino en otros de los poemas de Teillier, como en "Sentados frente al fuego", donde el tercer verso dice: "Miro el jarro de greda donde aún queda vino" (33), que en consonancia con "La fiesta", podría leerse como el cuerpo en el que todavía hay vida. Entonces el vino podría ser un regalo y el cielo liberado, es la liberación del sujeto, que finalmente logra escapar de la situación de desarraigo y actualizar su pasado con tanta fuerza que deja de ser un mero intento por recuperar el pasado para convertirse en vivencia efectiva: la infancia ya no es el paraíso perdido, sino el paraíso recuperado y reconstruido. He ahí la matriz específica de ese poema: la recuperación de la infancia. El sujeto entonces se salva, logrando apartarse de los fantasmas y las ruinas, optando por lo verdadero, de tal manera que la fiesta deja de ser un deseo y se convierte en realidad. Finalmente la boca ya no huye del canto, lo que estimo como el retorno de la palabra y de la facultad del lenguaje. Al eliminarse el quiebre de este último, el sujeto se reconoce a sí mismo y puede despojarse de los rostros inventados.

Pero, ¿cómo es posible esa recuperación? La salvación es posible mediante la muerte, a través de ella se logra la recuperación de la infancia. Para esto, me apoyo en Kristeva ${ }^{18}$, quien plantea que la aniquilación del cuerpo es posible porque se confía en la resurrección (2000: 124). En el poema la resurrección corresponde a la recuperación de la infancia, del cuerpo de niño. La muerte ha significado quitarse la máscara, pero lo que se ha aniquilado es el sujeto desarraigado, y la resurrección es, en este caso, la liberación del presente. Esa liberación total, el desprenderse de la identidad del sujeto adulto e inadecuado por completo, es lo que posibilita lanzarse hacia el pasado. Es interesante cómo se potencia la lectura del poema siguiendo a Kristeva, para lo cual vuelvo a retomar la presencia del pan y el vino, que en la tradición cristiana son símbolos del sacrificio de Jesús en la cruz, que es la condición por la cual la muerte da paso a la resurrección, en vez de significar un término definitivo. En este sentido, Kristeva plantea a Dios como ágape, por cuanto ama primero y se ofrece y como tal, "desciende ${ }^{l 9}$ : es don, acogida y gracia" (2000: 123). De la misma manera, en "La fiesta" es el vino el que desciende del cielo ya liberado, lo que conecto con mi apreciación anterior al respecto: es la vida actualizada, liberada de presente, porque el pasado se

${ }^{18}$ Para Kristeva, "[e]l amor se realiza por una muerte, ciertamente provisional”, y es provisional por cuanto el fin último es la vida, no en términos de eternidad simplemente, sino de resurrección (2000: 124).

${ }^{19}$ La cursiva es original del texto de Kristeva. 
ha convertido en presente de nuevo.

Volvamos a la hipótesis central: el sujeto lírico se encuentra en una posición de desarraigo e inicia un viaje a través de la memoria hacia la infancia, la casa familiar, la tierra natal. Ese viaje, decía, se hace desde su espacio biográfico, es por este motivo que encontramos en los poemas la novela familiar que nos habla de una familia sencilla, en que la preocupación y el cuidado se demostraban también en la alimentación y la manufactura casera de los alimentos. Ciertamente hay una metáfora ahí: cuando dice que “(...) en el viejo armario conservan su alegría el licor de guindas que preparó la abuela y las manzanas puestas a guardar", esos alimentos son el sujeto que en su infancia era feliz, cuidado y protegido por la abuela. El género aquí es relevante: la protección tiene sello femenino, por cuanto tradicionalmente es la mujer la que se ha ligado a las tareas domésticas, incluyendo la cocina. En el hipograma de Heidi, conscientemente opté por un cambio en esto, para indicar que los vínculos de cuidado en torno a la comida también pueden provenir desde lo masculino. Esto porque si la cocina es el "lugar bendito de una dulce intimidad" (Certeau, Giard y Mayol, 1999: 197), ésta no tiene por qué provenir exclusivamente del cuidado materno o femenino.

De hecho, aparte de "Otoño secreto" en los poemas de Teillier sólo hay otra referencia a la comida en manos femeninas: en "Sentados frente al fuego", dice "yo llenaba esa manos de cerezas, esas manos llenaban mi vaso de vino" (1995: 33). Pero no se trata de la madre, sino de la enamorada. Ahí el intercambio no es sólo de comida ni tampoco podemos entenderlo como un amor totalmente platónico, sino como una conexión sexual que es comprendida como de entrega recíproca: yo doy, tú das, yo recibo, tú recibes. El uno al otro se completan, se colman, en términos espirituales y físicos. Certeau nos hablará de la "fantasmagoría devoradora" ${ }^{20}$, que en este caso, está controlada a través de la ausencia de un verbo que explícitamente implique el comer, aunque sí usa llenar, que tiene sentido en términos de saciar el hambre del uno por el otro. La elección de esta palabra le da un sentido más amoroso -romántico- que erótico al texto, tal vez apelando a una imagen más idílica que lujuriosa, esto último quedando más bien elidido del texto, pero sin disminuir la potencia que tiene el considerar al cuerpo como amoroso.

En los poemas la comida tendrá también presencia como fundadora de comunidad, en tanto que se trata de un "comer en compañía" que crea

\footnotetext{
${ }^{20}$ Certeau habla al respecto de una metáfora caníbal y de fusión de los dos cuerpos. Para esto mencionará cómo en el lenguaje amoroso se utilizan palabras que tienen que ver con la comida: preparar, hambre, sed, devorar, comer (Certeau, Giard y Mayol, 1999: 202).
} 
y hace perdurar los lazos que unen a la familia o una colectividad mayor (Korsmeyer, 2002: 252). En este mismo sentido, Octavio Paz menciona al vino como complemento de la comida, cuyo objetivo sería "estimular las relaciones y las uniones que se anudan en torno a una mesa" (1981: 216). Observamos esto en "Día de feria", en que la comunidad que se está estableciendo -o reforzando- es la del campesino y también la reivindicación de los indígenas - las figuras de greda- que "viven hechas sangre en nuestra sangre, como el vaso de vino tinto" (Teillier 1995: 31). En el poema es más que compartir el vino, incluso, es beberlo y hacer que la sangre del campesino se una con la nuestra, lo que relaciono con una de las ideas de Carolyn Korsmeyer: al ingerir un alimento -como tomar vino en este caso-, implica que los alimentos "se convierten en uno" (2002: 254). Efectivamente en el poema, el vino pasa a constituir una parte del sujeto lírico: la sangre que se une a su sangre. La autora agregará que dado que comer "altera nuestra propia constitución, su ejercicio requiere de la confianza” (254), y qué situación de mayor confianza que unirse en la acción de beber el vino, de unir la sangre de todos.

La infancia y la adolescencia en las que se sumerge desde el presente el sujeto lírico, rescatan la historia familiar, pero también la de la comunidad, como en el caso de "Día de feria". En este sentido hay un carácter testimonial que arranca desde la perspectiva autobiográfica que ha guiado el texto: el testigo que está en "condiciones de ofrecer un testimonio" acerca de lo presenciado en esa época añorada (Agamben, 2000: 15) es Teillier. Recordemos que para Agamben una de las aproximaciones al concepto de testigo es verlo como aquel que "ha vivido una determinada realidad" (15). De tal forma, es un superviviente de su historia y no tiene más opción que recordar. En el caso de Teillier, al enfrentarse al testimonio nos da un relato que es poético, no mimético, sino profundo y metafórico. Por este motivo la posición de enunciación de los poemas es interesante. El sujeto habla desde la melancolía, desde la pérdida - del amor, del arraigo, de la historia familiar-, desde una situación que podemos tildar de rota y desde la cual se quiere volver al tiempo de la unidad, en que el ser estaba completo. Pero también se quiere dejar inscrita esa novela familiar construida desde el pan -que es el trabajo del hombre, la madre/abuela que amasa, la conexión con la tierra, la mesa familiar, el sujeto mismo-, el licor de guindas, la sopa caliente, la copa de vino, las cerezas. "El pan vuelve a ser trigo" (1995: 37), escribe Teillier en "La fiesta", está hablando del regreso al origen: la memoria recupera la historia familiar y la historia de la comunidad que se tejió desde la cocina. 
De la misma manera, cada momento en que tomo zapallo camote, zapallo italiano, repollo morado, zanahorias, tomate, papas, carne de vacuno y un poco de orégano para preparar la comida de mi hijo, con él viéndome desde su silla de madera, también estoy configurando una historia y un vínculo.

\section{REFERENCIAS}

Adorno, Theodor W. (2003). Notas sobre literatura. Madrid: Ediciones Akal. Agamben, Giorgio. (2000). Lo que resta de Auschwitz: El archivo y el testigo. Valencia: Pre-textos.

Arfuch, Leonor. (2002). El espacio biográfico. México: Fondo de Cultura Económica.

Ayuso de Vicente, María Victoria, García Gallarín, Consuelo y Solano Santos, Sagrario. (1997). Diccionario Akal de términos literarios. Madrid: Ediciones Akal.

Calderón, Alfonso. (1971). Aproximaciones a la poesía de Jorge Teillier. En Jorge Teillier, Muerte y maravillas. Santiago: Editorial Universitaria. . (2005). Antología de la poesía chilena contemporánea. Santiago: Editorial Universitaria.

Certeau, Michel de, Giard, Luce y Mayol, Pierre. (1999). La invención de lo cotidiano. México: Universidad Iberoamericana.

Forradellas, Joaquín y Marchese, Angelo. (1986). Diccionario de retórica, crítica y terminología literaria. Barcelona: Editorial Ariel.

Goic, Cedomil. (1992). Los mitos degradados: ensayos de comprensión de literatura hispanoamericana. Amsterdam: Editions Rodopi B. V.

Korsmeyer, Carolyn. (2002). El sentido del gusto: Comida, estética y filosofía. Barcelona: Paidós.

Kristeva, Julia. (2000). Historias de amor. México: Siglo XXI.

Lejeune, Philippe. (1991). El pacto autobiográfico. Suplementos Anthropos, 29, 47-61.

Mistral, Gabriela. (2010). Antología. Perú: Alfaguara.

Nómez, Naín. (1992). Poesía chilena contemporánea: Breve antología crítica.

Santiago: Editorial Andrés Bello y Fondo de Cultura Económica.

Paz, Octavio. (1981). El ogro filantrópico. Barcelona: Seix Barral.

Pozuelo Yvancos, José María. (2006). De la autobiografía. Teoría y estilos. Barcelona: Editorial Crítica.

Ricoeur, Paul. (2001). Metáfora viva. Madrid: Trotta. 
Riffaterre, Michel. (1984). Semiotics of poetry. Bloomington: Indiana University Press.

Rubio Tovar, Joaquín. (2005). La Vieja Diosa: de la filología a la posmodernidad. Alcalá de Henares, España: Ediciones del Centro de Estudios Cervantinos.

Spyri, Juana. (2000). Heidi. Madrid: Ediciones RIALP.

Teillier, Jorge. (1995). Para ángeles y gorriones. Santiago: Editorial Universitaria.

Valdivieso, Jaime. (1997). La otra realidad de Teillier. Revista Trilce, 1. Disponible en http://www.uchile.cl/cultura/teillier/estudios/3.html. 